\title{
Intervention in Potential Leukemic Cell Migration Pathway Affects Leukemogenesis *
}

\author{
A. Peled and N. Haran-Ghera
}

\section{A. Introduction}

Several factors are involved in the high frequency of T-cell lymphomas of AKR mice, which appear mainly in the thymus at the age of 6-12 months [1]. The thymus is considered to play a major role in the disease since its removal prevents the development of T-cell lymphoma [2], while retransplantation of thymic epithelium to thymectomized AKR reconstitutes the high frequency of lymphoma [3]. Although the AKR/J strain has the predisposition to develop the disease since birth [4], the mean latent period is delayed until the age of 8 months. The long latent period has been attributed to the delayed formation of the leukemogenic dual tropic virus (DTV) with the MCF characteristic $[5,6]$, formed in the thymus as a consequence of recombination within the envelope gene of ecotropic and xenotropic murine leukemia virus (MuLV). DTVs are detected only in preleukemic thymus and leukemic tissues of strains of mice prone to develop high incidence of leukemia [7]. DTVs enhance leukemia development whereas endogenous ecotropic or xenotropic viruses are usually nontumorigenic. Exceptional is the ecotropic virus isolate $\mathrm{SL}_{3}$ with the enhancing activity on T-cell lymphomagenesis [8]. These observations support the assumption that DTVs are proximal

\footnotetext{
Department of Chemical Immunology, The Weizmann Institute of Science, Rehovot 76100 , Israel

* This research was supported by grant from the "Ebner Family Leukemia Research Foundation at the Weizmann Institute of Science, in memory of Alfred Ebner."
}

transforming agents of thymocytes and thereby responsible for high incidence of T lymphoma in AKR mice. Cloyd [9] proposed specific cellular tropism of two subclasses of MCF virus, and claimed that oncogenicity is closely linked to cellular differentiation. MCF isolated from lymphomatous thymus was replicating in the thymus and $\mathrm{T}$ peripheral cells, while nonlymphomagenic MCF isolated from leukemic spleen of NFS mice did not replicate in the thymus but rather in bone marrow cells, spleen, and lymph node Blymphocytes.

Our previous studies showed that potential leukemic cells (PLCs) are initially detected among bone marrow cells rather than in the thymus of young AKR mice [10]. Infection of 14-day-old AKR mice with DTV did not change the spontaneous PLC distribution pattern in the host organs; however, it enhanced PLC transition to autonomous leukemic cells. A preferential cell tropism of DTV to cells among bone marrow and spleen cells rather than from thymocytes was also demonstrated [11]. We therefore considered DTV as a promoter of PLCs, triggering the natural progression and transition of PLCs into frank autonomous lymphoma. Very recently Buckheit et al. [12] proposed that a certain fraction of bone marrow cells in the AKR mouse enriched in prothymocytes is also high in ecotropic virus-producing population, seeding the spleen and thymus with infectious ecotropic virus. These cells may represent the PLCs in the bone marrow of AKR mice demonstrated by us $[10,11]$.

Removal of the thymus that prevents the emergence of $\mathrm{T}$-cell lymphoma did 
not eliminate the presence of dormant PLCs among lymphoid organs of 8- to 12-month-old thymectomized AKR mice (thymectomy performed at the age of 50-60 days). Transplantation of lymphoid cells from these thymectomized mice into the appropriate recipients yielded $80 \%-100 \%$ incidence of $\mathrm{B}$ cell lymphoma of $\mathrm{AKR} / \mathrm{J}$ origin [13]. $\mathrm{MCF}$-type viruses are probably not involved in the generation of these lymphomas. Most of the tested tumors were found negative to the monoclonal antibody $18-5$, which recognizes $\mathrm{MCF}$ expression. Lack of recombinant virus formation was also observed in AKR strecker mice (athymic mutant) [14]. However, recent work by Fredrickson et al. [15] suggested a possible contribution of ecotropic MuLV in the development of B-cell lymphoma in NFS mice. Viral isolates from B-cell lymphomas of AKR origin were found to inhibit spontaneous T-lymphoma development [16]. One of the viral isolates CFC-666 was actually found to interfere with the spontaneous DTV formation in the thymus, thereby perhaps preventing the spontaneous T-cell lymphomagenesis in AKR mice. In the present study we further extended our analysis of the events occurring following infection with CFC-666 virus, and its effects on thymus differentiation antigens and on the occurrence of PLCs.

\section{B. Results}

The age-dependent susceptibility of AKR mice to the effect of CFC-666 shown previously to prevent spontaneous T-cell lymphoma development [16] was tested. Female and male newborn to 2-day-old AKR/J mice were injected i.v. (through the orbit plexus of the eye) with $0.1 \mathrm{ml} \mathrm{CFC}-666$ or intrathymically into 14-, 60-, or 120-day-old AKR/J mice. The lymphoma incidence and the phenotype of the emerging tumors are shown in Fig. 1. A remarkable suppression in the development of $\mathrm{T}$-cell lymphoma was observed in mice injected when newborn or 14 or 60 days old $(27 \%, 16 \%$, and $32 \%$, respectively). A low incidence of B-cell lymphoma (about 20\%) developed in the newborn and 14-day-old injected mice with CFC-666. The suppressive effect on T-cell lymphoma development was not observed when CFC-666 was injected into the thymus or spleen of 120 day-old mice. These mice yielded a $95 \%$ T-cell lymphoma incidence within 250 days, similar to the PBS intrathymic-injected mice or untreated controls.

Since CFC-666, when injected into young AKR mice, prevents leukemia development, it could also affect the occurrence of PLCs, their distribution, and their site. The presence of PLCs in thymus, bone marrow, or spleen of mice 12 months after CFC-666 injection into the thymus of 14-day-old AKR mice was demonstrated. Although mice injected with CFC-666 developed only $20 \%$ of lymphomas, $70 \%-90 \%$ of such infected mice were found to be carriers of PLCs. The majority of the lymphomas had preB-B characteristics, and sporadic occurrence of $\mathrm{T}$ - or null-cell lymphomas was also observed (Haran-Ghera et al., this issue).

These results resemble those of our previous observation of the existence of dormant PLCs in thymectomized AKR mice $[13,17]$, in spite of the fact of the presence of an intact thymus (although changed phenotypically). Thus, infection of young mice with CFC-666 might cause a "physiological thymectomy", thereby preventing PLC migration from the bone marrow to the intact thymus for further development into $\mathrm{T}$-cell lymphoma.

The preleukemic thymus of AKR/J involves changes in thymocyte subpopulation and in viral expression observed at the age of 5-6 months [7]. The formation of the dual tropic virus (DTV) in the thymus within this age range has been related to those preleukemic changes. These changes could be accelerated by injection of DTV intrathymically to young AKR/J mice $[11,18]$. The injection of CFC-666 into the thymus of 14-day-old mice pre- 
Fig. 1. Age-dependent susceptibility to CFC-666. Female and male new-born to 2-day-old AKR/J mice were injected i. v. $(0.1 \mathrm{ml}) ; 14-$, 60-; or 120-day-old mice were injected intrathymically $(0.02 \mathrm{ml})$.

Lymphoma incidence and phenotypes
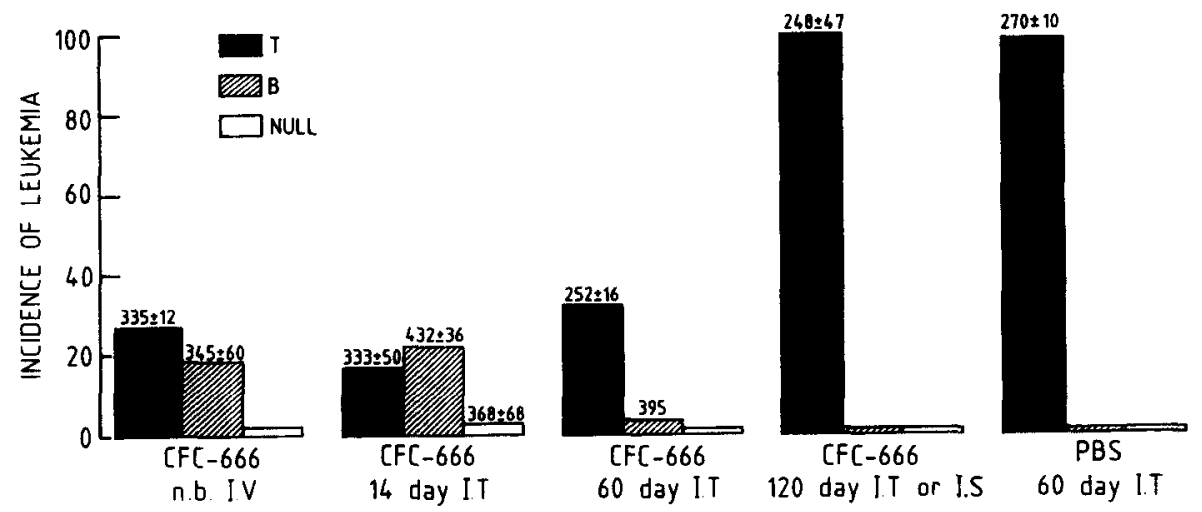

vented the changes occurring in the thymus of $A K R / J$ spontaneously (or induced by DTV injection), namely the gradual elevation of class I histocompatibility antigens $(\mathrm{H}-2 \mathrm{~K}$ and $\mathrm{H}-2 \mathrm{D})$ and viral antigens, especially the expression of DTV [16]. In the present studies we further extended the investigation concerned with changes of thymus subpopulation in terms of quantitative expression of thymocyte differentiation antigens Thy-1, Lyt-2, and L3T4. The level of Thy 1.1 did not change during the first 9 months following CFC-666 inoculation and was similar to normal 2-month-old untreated mice, but dropped strikingly at 12 months post CFC-666 inoculation to about $36 \% \pm 17 \%$ and a new population of $\mathrm{Ig}^{+}$cells appeared in these thymi (Fig. 2). The use of Lyt-2-FITC and L3T4-PE antibodies in FACS 440 analysis enabled us to calculate the level of the four populations of the thymus: Lyt- $2^{+}$ $\mathrm{L}_{3} 4^{+}{ }^{+} \mathrm{Lyt}_{-2}{ }^{+} \mathrm{L}_{3} 4^{-}{ }^{-} \mathrm{Lyt}^{-} \mathrm{L}_{3} 4^{+}$, and $\mathrm{Lyt}^{-} 2^{-} \mathrm{L} 3 \mathrm{~T}^{-}{ }^{-}$. In the normal adult mouse, Scolly et al. [19] found $81 \%, 5 \%$, $9 \%$, and $5 \%$, respectively. In our studies (results presented in Fig. 3) we obtained the following: In (A) 2-month-old thymus and in (B) 9-month-old healthy thymus the four groups comprised $70 \%$, $10 \%, 12 \%$, and $8 \%$, respectively. Although the pattern of distribution of cells within the group was different, the overall percent age of cells in each group was similar in both ages. These results are dramatically changed in the thymus of

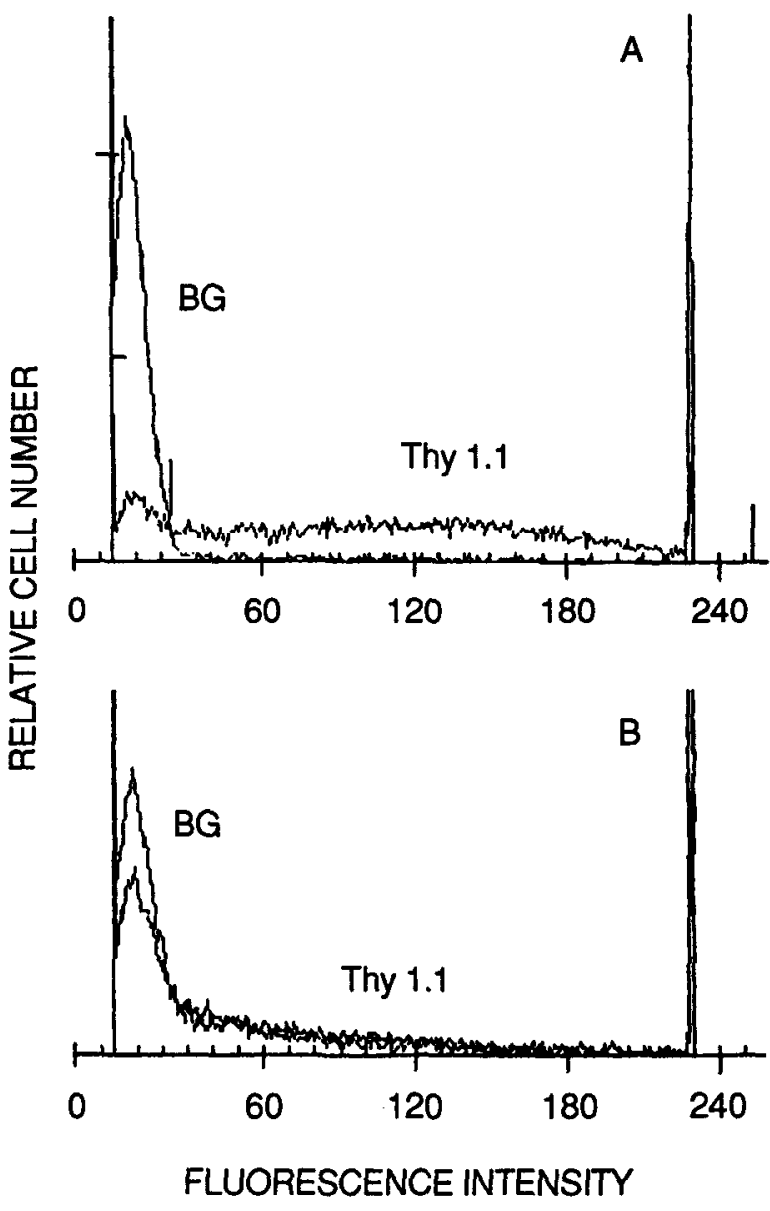

Fig. 2A, B. FACS II analysis of AKR/J thymus for Thy 1.1 expression. A Normal thymus of 9-month-old AKR/J mice. B CFC-666-inoculated thymus (i.t. at 14 days) 12 months following virus inoculation

CFC-666-injected mice. (C) At 9 months following CFC-666 inoculation, the thy-

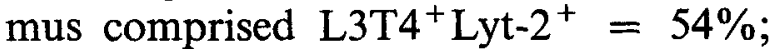
${\mathrm{L} 34^{+}}^{+}$-Lyt-2 $=15 \%$; L3T4 ${ }^{-}-\mathrm{Lyt}_{-} 2^{-}=$ $14 \%$; L3T4 ${ }^{-}-$Lyt $-2^{+}=17 \%$. (D) Twelve months following CFC-666 inoculation the thymus changed its phenotype com- 

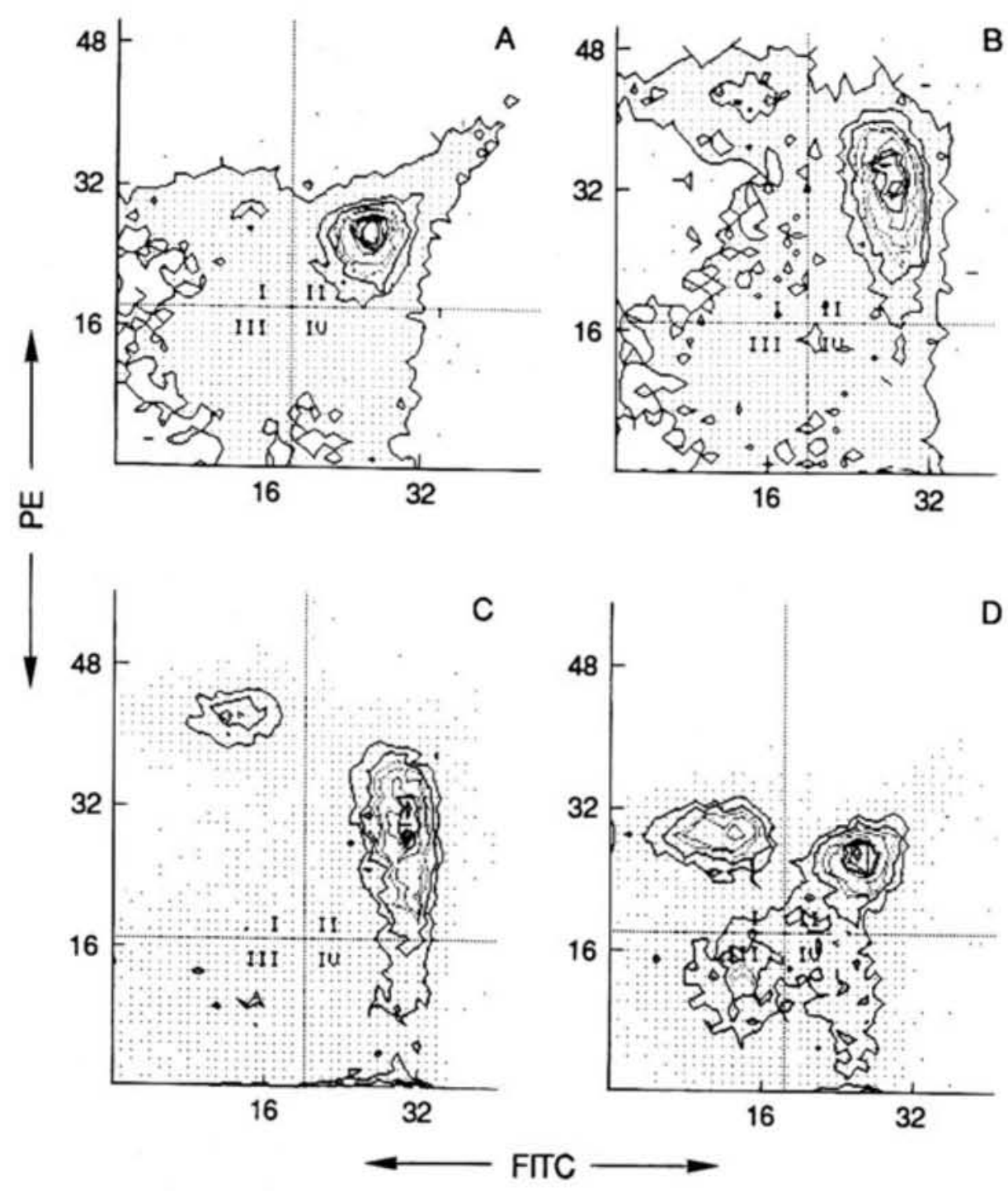

Fig. 3A-D. FACS

440 analysis of AKR/J thymus for Lyt-2 and L3T4 expression by double labeling using Lyt-2FITC and L3T4-PE. A Two-month-old thymus. B Ninemonth-old thymus. C CFC-666-inoculated thymus (i.t. at 14 days old) 9 months following virus injection. D Thymus 12 months following CFC-666 injection

pletely and the subgroups comprised $33 \%, 27 \%, 21 \%$, and $19 \%$, respectively. The thymi of CFC-666-injected mice remained normal in size but underwent changes in the expression of differentiation antigens.

\section{Conclusion}

In the studies described here we observed that the susceptibility to prevent spontaneous T-cell lymphomagenesis following injection of CFC-666 virus isolated from B-cell lymphoma of AKR origin is age dependent since the virus has to be injected early in life. The characteristic changes occurring spontaneously in the thymus of AKR mice during the preleukemic phase (at the age of 5-6 months) or following $\mathrm{MCF}$ injection were prevent- ed by the inoculation of CFC-666. Namely, the amplified class I histocompatibility antigens, $\mathrm{H}-2 \mathrm{~K}^{\mathrm{k}}$ and $\mathrm{H}-2 \mathrm{D}^{\mathrm{k}}$, and especially the viral expression of MCF, were not observed. Nevertheless, dramatic changes in thymus differentiation antigens took place in the CFC-666-injected mice. Thus, CFC-666 interferes with MCF formation or replication in the thymus. We have suggested previously that DTV-induced changes in the thymus, including its "thymolytic" effect, trigger preexisting PLC migration from bone marrow into the thymus, thereby providing a suitable microenvironment for PLC progression to T-cell lymphoma. However, CFC-666 interference with this process might intervene also with the migration pathway of PLCs into the thymus, thereby allowing PLC dormancy. CFC-666 injection did not af- 
fect the presence of PLCs in the infected mice and only a low level of PLCs was observed in thymus of 12-month-old mice versus high PLC incidence observed in thymus of untreated 7- to 10-monthold mice. The PLCs demonstrated among bone marrow, spleen, and thymus cells eventually developed into B-cell lymphoma upon transplantation to new hosts (see Haran-Ghera et al., this issue). Reduced T-cell lymphoma development in AKR mice was demonstrated by the injection of DTV-SMX-1 into neonates [20]. Similarly, the prevention of spontaneous B-cell lymphoma development was observed by De Rossi et al. [21] following treatment of $\mathrm{SJL} / \mathrm{J}\left(\mathrm{V}^{+}\right)$neonate mice with a DTV-SJL-151. In both cases the authors suggested viral interference as a plausible explanation for their observation.

\section{References}

1. Furth J, Seibold HR, Rathbone RR (1933) Experimental studies on lymphomatosis of mice. Am $\mathrm{J}$ Cancer 19:521-527

2. McEndy DP, Boom MB, Furth J (1944) On the role of thymus, spleen and gonads in the development of leukemia in high leukemic strain of mice. Cancer Res $4: 377-383$

3. Hays E (1968) The role of thymus epithelial reticular cells in viral leukemiogenesis. Cancer Res 28:21

4. Rowe WP, Pincus T (1972) Quantitative studies of naturally occurring murine leukemic virus injection of AKR mice. $J$ Exp Med 135:429-436

5. Hartely JW, Walford MK, Old LJ, Rowe WP (1977) A new class of mouse leukemia virus associated with development of spontaneous lymphomas. Proc Natl Acad Sci USA 74: 789-792

6. Elder JH, Gautsch JW, Jensen FC, Lerner RA, Hartely JW, Row WP (1977) Biochemical evidence that MCF murine leukemic viruses are envelope (ENV) gene recombinants. Proc Natl Acad Sci USA 74:4676-4680

7. Kawashima K, Ikeda H, Hartley JW, Stockert E, Rowe WP, Old LJ (1976)
Changes in expression of murine leukemia virus antigens and production of xenotropic virus in the late preleukemic period in AKR mice. Proc Natl Acad Sci USA 73:4680-4684

8. Hays EF, Levy JA (1984) Differences in lymphogenic properties of AKR mouse retroviruses. Virology 138:49-57

9. Cloyd MW (1983) Characterization of target cells for MCF viruses in AKR mice. Cell 32:217-225

10. Haran-Ghera $N(1980)$ Potential leukemic cell among bone marrow of young AKR/J mice. Proc Natl Acad Sci USA 77:29232926

11. Haran-Ghera N, Peled A, Hoffman AD, Leef F, Levy JA (1987) Enhanced AKR leukemogenesis by dual tropic viruses. I. The time and site of origin of potential leukemic cells. Leukemia 1:442-449

12. Buckheit RV Jr, Bolognesi DP, Weinhold KJ (1987) The effects of leukemosuppressive immunotherapy on bone marrow infectious cell centers in AKR mice. Virology $157: 387-396$

13. Peled A, Haran-Ghera N (1985) High incidence of $\mathrm{B}$ cell lymphomas derived from thymectomized AKR mice expressing TL.4 antigen. J Exp Med 162:1081-1086

14. Bedigian HG, Shultz LD, Meier H (1979) Expression of endogenous murine leukemic viruses in $A K R / J$ Strecker mice. Nature 279:434-436

15. Fredrickson TM, Morse HC III, Rowe WP (1984) Spontaneous tumors of NFS mice congenic for ecotropic murine leukemic virus induction loci. J Nat Cancer Inst 73:521-524

16. Peled A, Haran-Ghera N (1988) Prevention of $\mathrm{T}$ cell lymphoma in $\mathrm{AKR} / \mathrm{J}$ mice. Leukemia 2:125-131

17. Haran-Ghera N, Trakhtenbrot L, Resnitzky P, Peled A (1989) Preleukemic state in murine leukemogenesis. Leukemia (in press)

18. O'Donnell PV, Nowinski RC, Stockert E (1982) Amplified expression of murine leukemia virus (MuLV)-coded antigens on thymocytes and leukemic cells of AKR mice after infection by dual tropic (McF) MuLV. Virology 119:450-464

19. Scollay R, Bartlett P, Shortman K (1984) $T$ cell development in the adult murine thymus: changes in the expression of the surface antigens Ly-2, L3T4 and B2A2 during development from early precursor cells to migrants. Immunol Rev 82:79-87 
20. Stockert E, O'Donnell PV, Ohata Y, Old LJ (1988) Inhibition of AKR leukemogenesis by SMX-1, a dual tropic murine leukemia virus. Proc Natl Acad Sci USA 77:3720-3724
21. DeRossi A, D'Andrea E, Biasi G, Gollavo D, Chieco-Bianchi L (1983) Protection from spontaneous lymphoma development in $\mathrm{SJL} / \mathrm{J}\left(\mathrm{v}^{+}\right)$mice neonatally injected with dual tropic SJL/151 virus. Proc Natl Acad Sci USA 80:2775-2779 